\title{
Can politically oriented interventions in built heritage contribute to its authenticity? Erbil Citadel's Babylonian Gate as a case study
}

\author{
Mohammed Awadh Jasim ${ }^{1 *}$, Laura Hanks ${ }^{2}$ and Katharina Borsi ${ }^{2}$
}

\begin{abstract}
Today, the concept of built heritage authenticity is a projection screen for conflicting demands and thus a 'contested field'. Short-sighted readings started to drag the concept behind different ill-considered treatises, in which some heritage aspects loosely outweighed other aspects. Archaeological perspectives that tend to freeze heritage structures in time, such as those that are privileged upon other contemporary socio-cultural issues, while political takes also overshadowed other epistemological prospects, and vice versa. Repercussions have made inclusion of what is regarded as 'inevitable changes' within the built context problematic as to the re-interpretation and thus assessment of its authenticity. Despite their possible momentary threat to the latter, these changes may add to the cultural value of the context over time, granting new potential that may instead boost its authenticity. This paper investigates the potential continuity of Erbil Citadel's Babylonian Gate as an inevitable change within the site's built context by studying the Gate's controversial political impacts on the context's authenticity. This study affirms that authenticity is a transcendental value of an open-ended progressive nature, which cannot be reduced to a specific period or properties within the historical chronology of built heritage. Hence, authenticity should be approached as a meaningful existential issue, while revelation of its essence and thus its dimension entails precise scrutiny of both the tangibles and intangibles of the context. However, to be part of its authenticity, any change in the context should be adaptable and possibly incorporated as a new value within its cultural strata, thus enabling progressive support for site authenticity.
\end{abstract}

Keywords: Progressive authenticity, Heritage conservation, Political interventions, Inevitable changes, Erbil Citadel's Babylonian Gate

\section{Introduction}

At present, contradictory treatises on built heritage have led authenticity concept to be a 'contested field', 'beset by a bitter clash of values' (Weiler and Gutschow 2017, xvii), which either address heritage remnants as 'physical history', or immaterial residues of 'cultures'. This contradiction is largely attributed to

\footnotetext{
* Correspondence: mohammed.awadh@koyauniversity.org

${ }^{1}$ Department of Architectural Engineering, Koya University, University Park,

Danielle Mitterrand Boulevard, Koya, Kurdistan Region KOY45, Iraq

Full list of author information is available at the end of the article
}

'emblazoning identity, safeguarding the national patrimony, or fashioning a concept of "world heritage". However, the subjective insights that lack a conceptual basis, particularly regarding embedment of some inevitable changes to its definition, make the concept 'risky' (Little and Shackel 2014, 43). A 'foggy judgement', as Conran (2006) notes, against any potential political implications that these changes incorporate, mostly subjects the concept to what Lowenthal (1998, 6) refers to as a state of preordained 'dismay'. This often steers the essence of authenticity to be 
'suppressed or unclear' due to some loose inputs about its value (Little and Shackel 2014, 43), which usually partially efface the true history of the built context. Some political interventions, with their consequences, have indeed become integral to the cultural panorama of many built heritage contexts, while assessment of their contribution to context authenticity may require a precise reading regardless of their denotations (Wright 2001, 179). Perhaps the issue of Erbil Citadel's grand gate can be regarded as part of this discourse.

Erbil Citadel is 'an ancient city built on top of an artificial mound $[\mathrm{Tell}]^{1}$ raised up by successive rebuilding of ... structures on top of each other over thousands of years' (Jasim et al. 2017, 294). Due to a contentious site renovation plan, its grand gate was demolished in the late 1970 s and replaced by a new version, locally called the Babylonian Gate 'BG', due to some similarities in form with the architecture of Babylon. The current existence of the BG on the site (in terms of its form, history and cultural values) raises controversy about the authenticity of the Citadel's heritage being, according to Novacek et al. (2008) and ICOMOS (2014), dissonant with the urban context of the site and thus unable to represent the traditional spirit of its architectural character. Importantly, the BG's existence on the site, based on some treatises, has subsequently been laden with extraneous political connotations. Therefore, the current revitalisation site plan suggested a new proposed design 'PD' to replace the $\mathrm{BG}$, which aims to retrieve the original settings of the old/original gate (HCECR 2012c). Implementation of the PD was initiated in 2014, but due to some financial issues, the plan has experienced some delays, making the current structure of the grand gate a mixture of the BG and the PD. While two main parts of the BG are still erect on the site, the PD's central part has currently replaced its counterpart of the BG (replacing the BG's circular arch with the pointed arch of the original gate) (Fig. 1).

However, recently, the issue of complete demolition of the two remaining parts of the $B G$ has sparked fresh controversy locally, which the study investigates. Despite its limited duration on the site, the BG may be documented as a new cultural layer to the 'authenticity of setting' of Citadel's built heritage. It records a critical period of the modern history of the site, which involves some political implications of the former regime of Saddam Hussein (Brammah 2009a, 90). Such an implication may complement the site's historical-cultural story and thus may add to its authenticity. Therefore, this

\footnotetext{
${ }^{1}$ This mound is locally called Tell
}

controversy about determining the retention of the BG's remaining parts on the site may call for investigating their potential for the site's authenticity and perhaps through more contemporary assessment of its worth. The controversy put forward here is an endeavour to conceptualise ideas on how immaterial repercussions of some inevitable changes may add to authenticity of a built heritage constituent, deemed to be part of the deep history of the site.

The methodology used relies on a qualitative approach that first reviews, within an analytical framework, the main concepts in which the authenticity concept is being framed within the paradigm of built heritage, both historically and culturally. Second, the study narrates the historical-cultural record of the gate through a precise evidence-based analysis concerning its architectonic features, seeking any potential aspects of authenticity of the gate, in addition to accentuating any changes or deformations that its structure has undergone over history. Thus, the site's archival data on the features, material and spatial order of the gate were analysed; specific literature on the concept of authenticity in general and within Erbil Citadel in particular was reviewed; and semi-structured interviews were conducted among the site's indigenous inhabitants. The interviews centred on certain participants who share a rich cultural history with the site, and accordingly, their involvement can truly nourish the study with valuable input. Evidencebased 'participation [of] indigenous people' of the site may assist in clear identification of built heritage authenticity (UNESCO 2005; ICOMOS 2008b, 14). Then, the study carefully mapped those professionals among the indigenous inhabitants, whose views can be more informative, which was a challenge since the majority of the residents left the area after the site's evacuation step in 2006 for the purpose of its rehabilitation. Based on Von Droste and Bertilsson (1994), the current combination of features of the grand gate should be treated through a progressive approach that addresses the diverse cultural themes and events merged in its physical structure more adaptively to maintain the continuity of its authenticity. Progressive conservation policy often aims to stand at an equal distance from all the historical-cultural layers of the Citadel's built heritage context without detracting from any potential contribution or affecting any true value at the expense of another. According to a chronological reading, the study seeks to incorporate and thus preserve any input documenting particular tangible and intangible events and values, which may later add to the authenticity of the context. This approach facilitates a more qualitative understanding regarding whether the BG can truly enhance the originality of the site, which is what the study ultimately declares. 

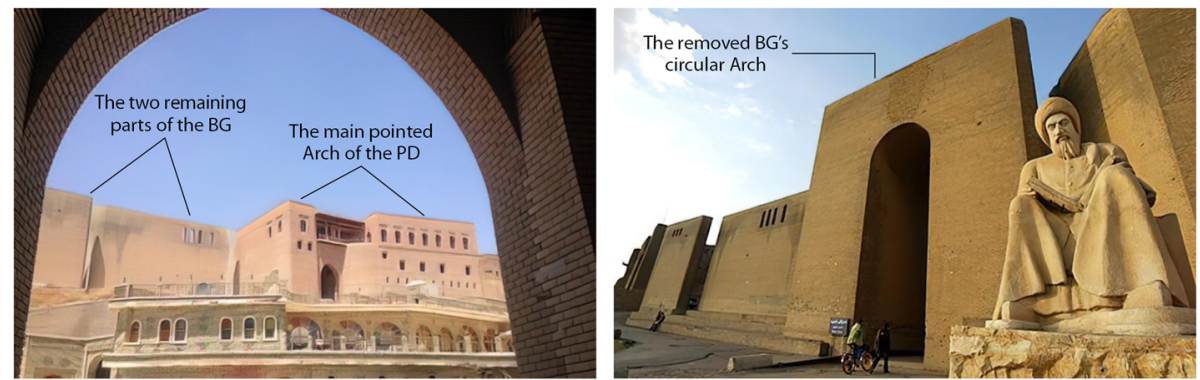

Fig. 1 Left: the PD's pointed arch, 2017 (Source: the author). Right: supersedes the BG's circular arch (Source: site archival data)

\section{Authenticity as an ill-defined concept in built heritage contexts: building a conceptual framework}

Given the significance of the concept in the field of 'conservation practice' (Nara ICOMOS), authenticity has been intermingled with numerous physical-historical or nonphysical cultural themes (as tangibles and intangibles) over time, communicated as ascribed values taken from multicultural origins (Weiler and Gutschow 2017). For instance, it has been associated (as something inextricable) with 'identity and integrity', 'patina/age value', 'memory', 'the spirit of the place' and 'heritage intangibles' at different sites (Han 2011, 64, Lowenthal and Jenkins 2011). Whereas the concept should have been carefully examined here to be precisely applied, it has been subjected to a loose-and even discordant-use with heritage interpretive values and culturally combined components, thus increasingly unleashing connotations and implications of the concept to ultimately undergo some subjective narratives (Weiler and Gutschow 2017). As a result, this drags the concept apart from its significations in some built contexts, impacting their accumulated historical values in the long run.

The globalised discourse on authenticity, on the other hand, has also led to limiting the concept with an imported unidimensional reading regarding the interpretation of some of its meaning, such as truthfulness and credibility, which excessively venerates authenticity 'as if it were a value in its own right' (Stovel 2007, 28). However, what is truthful and credible 'definitely depends on the context [s]' of these sites as historical events and cultural inputs entrenched and thus originating as home-grown realities (Weiler and Gutschow 2017, 1). Instead of corroborating an all-inclusive relevant meaning of the concept, this mostly led to imprinting the concept as 'universal', to be driven towards 'a substantial loss of credibility', which is largely produced by a Eurocentric constitution of the relevant standards of the concept, apparently influenced by the occidental cultures (Weiler and Gutschow 2017, 2). Application of these standards on some Asian sites, according to Stovel $(2008,15)$, drives authenticity's essence to 'meaningless statements', being merely an imitation of the outward physical settings of their contexts that rest on grounds completely different from those of occidentals. Gutschow (2010) and Lowenthal and Jenkins (2011) note that this makes the concept lack an inherent meaningfulness when it denotes meanings invented apart from the epistemological cultural ethos of these sites, which cannot originate in the privacy of their local realms. Consequently, they cannot respond to continuously changing cultural entities; thus, their transcultural grounds, particularly many of them, merge diverse political layers where their tangible and intangible aftermaths of the built context have become inescapable. In fact, this has instead addressed authenticity concept as 'a philosophical dilemma' (Stubbs 2009, 133), which largely inhibits its objective continuity, especially regarding some inevitable changes the context may experience as a response to some political circumstances (Poria et al. 2006).

Today, some political implications, including their impacts, have indeed become integral to the cultural panorama of many built heritage contexts. A rich body of literature recognises built heritage as a physical product of constant cultural assemblies of diverse values and events, whereas political inputs may form a concrete part of it and thus should be granted a genuine priority in understanding its authenticity. In Jokilehto's words, the matter is therefore about endorsing more 'culturalpolitical awareness', accordingly 'about deciding' how such inputs can make 'meaning of authenticity' more pertinent with the context, and consequently more objective in representing its values (ICOMOS 2008b, 48). Hence, Oyaneder $(2019,190)$ states that shaping a viable 'future' for built heritage authenticity should have real synchronisation with themes such as 'politics', since some inevitable political repercussions have led to embedding some genuine shifts in the cultural structure of built heritage that left real consequences for its authenticity.

However, loose interpretations of its political implications embed it in a state of outward objectivity ostensibly transmitted to the domain of heritage conservation, 
making it 'a projection screen for conflicting demands' (Weiler and Gutschow 2017, xviii), which often direct it either towards predetermined interests or assault its essence with irrelevant diagnoses. In contrast, from an ideological perception, Golomb (1995) states that authenticity rejects subordination to any qualities (though inherent in the context) that may display it as a 'rigid a priori essence' and nonprogressive. Authenticity refuses to comply with any 'given set of [preset] standards' in substantiation of these qualities (Golomb 1995, 12). It forms its objectivity by its own authority and does not accept narratives forced on its essence by outside subjectivity. Its objectivity is based purely on its inner properties that originate from the context in which it settles, then re-originates its form based on the potential of the context, but importantly through an all-encompassing vision for its diverse cultural assets over its history.

As such, the contemporary relevance of built heritage authenticity should perhaps be distilled through an epistemological reading that perceives the concept as 'pathos of incessant change' (Golomb 1995, 12) and thus as a 'transformed concept' that should respond to the continuously changing 'cultural contexts and local concerns' through a more liberated perspective (Weiler and Gutschow 2017, xviii). It is a perspective that should be 'negotiable' to stand at the same distance from the entangled cultural layers and concerns of built heritage and hence respond to contemporary issues of built environments more progressively. Moreover, it leaves behind the archaic ideologies and archaeological traditions that aim to 'freeze' an old structure in time and instead involve a variety of meanings, interpretations and practices of diverse (but precise) socio-cultural settings. Incorporation of the concept within any heritage component should therefore be 'beyond its [stagnant] purview' identified in some norms, based on some points (Weiler and
Gutschow 2017, xxi). First, scrutiny of the genuine cultural structure should involve truthful ideological themes, apart from any 'uniform application of standard solutions' on the cultural-historical specifics of the property, without invalidating any specific time period within its historical chronology (Beijing Document on the Conservation and Restoration of Historic Buildings in East Asia 2007; UNESCO 2015). Furthermore, we examine all values attached to the context throughout its history, including those acquired due to political interventions and regardless of the intention behind their denotations (Wright 2001).

\section{Erbil Citadel's grand gate: historical (culturally oriented) record}

Historically, Erbil Citadel's urban manifestation, based on (HCECR 2008; HCECR 2012a), and SOITM (2013), had only a main gate that was located on the south side of the site's perimeter wall. The gate served as a main entrance of the Fortress, which is currently called the grand gate. This feature of singularity, over time, has bestowed on the site more uniqueness as a fortified settlement in Mesopotamia, and has reinforced resistance to local political conflicts and outside threats, being adjacent to Persia. Tracing its physical growth, the gate has suffered destruction throughout its history, ensuring continuous alterations of its form and structure, resulting from the continuous collapse of the site, especially its mound-slope 'Tell'. The Tell is an archaeological pile of physical accumulations amassed as a result of successive colliding civilisations that have inhabited the site over history, heightening the historical-cultural value of the built context, of which the gate is part (Novacek et al. 2008; Brammah 2009b; Progetti 2012) (Fig. 2). However, as part of its architectonic act, its continuous collapse has also subjected the gate's structure to some

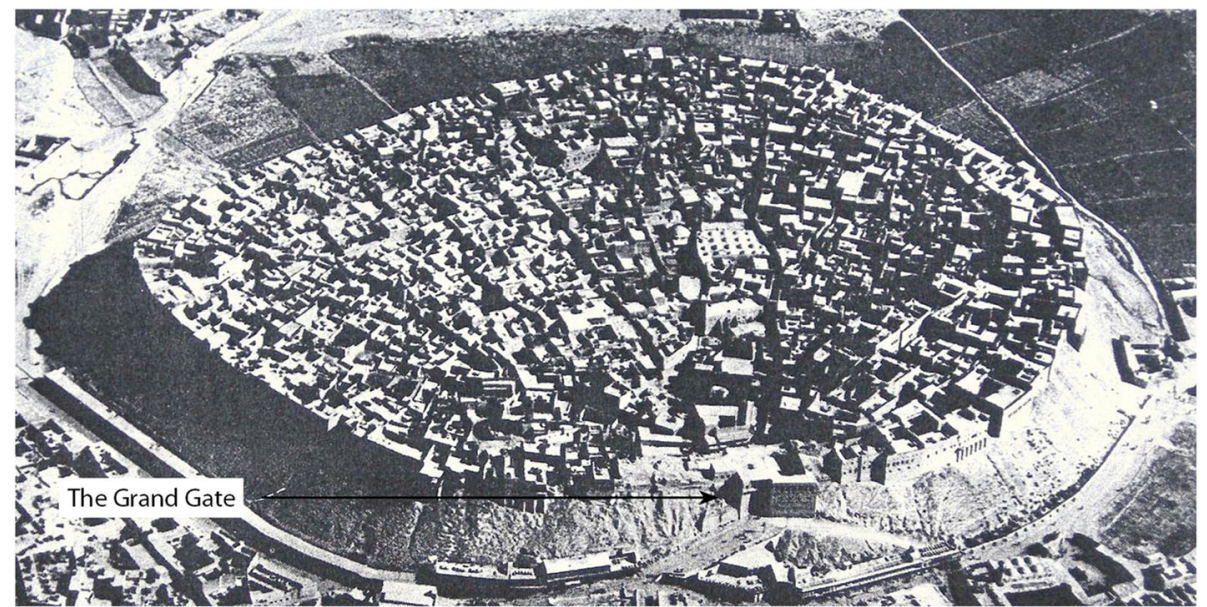

Fig. 2 The grand gate dominates the relationship between the urban context of the Suq and the Citadel, an aerial image for the site in 1951 (Source: Brammah 2009a, 91) 

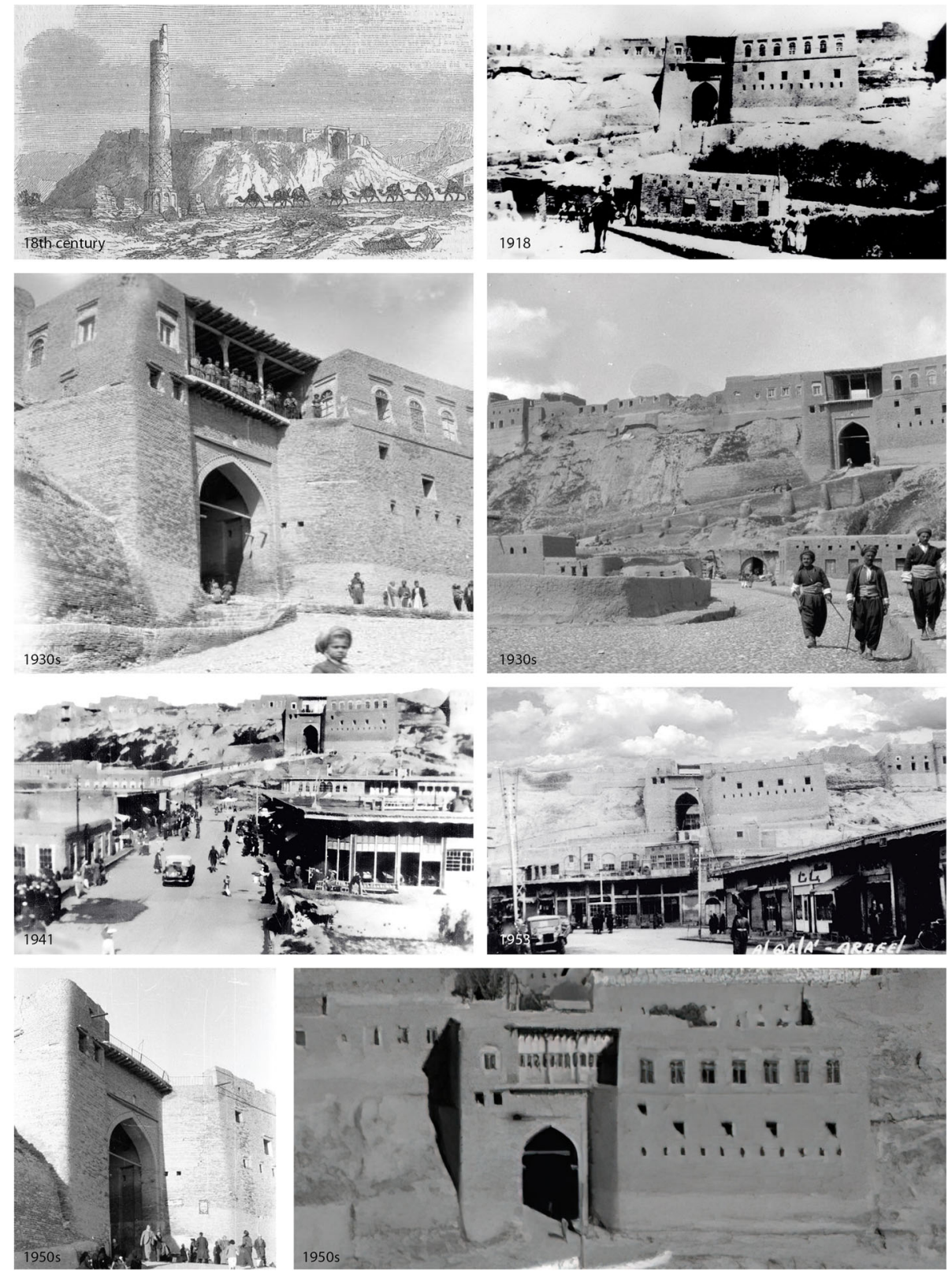

Fig. 3 The grand gate historical modifications between the end of the 19th century and the middle of the 20th century (Source: HCECR 2012b)

defects and fragility, thus to some modifications, over time.

For instance, based on HCECR (2008, 2012a, 2012b); SOITM (2013), Novacek et al. (2008), in the NeoAssyrian period- $657 \mathrm{BC}$, the gate was composed of two towers surrounding the Arch of the entrance. In 12581259 , and during the Mongol invasion, a new layer was added to its façade, which incorporated slightly different architectural features and elements, with new domes covered with turquoise and blue tiles on both sides. At the beginning of the 18th century, the gate was mostly reconstructed due to the fragility of its structure, which influenced some of its outer details. During the mid18th century, as part of evolving socio-cultural assets, the spatial design developed a simple entrance passage of a pointed arch that was located under the middle of the mound slope. In 1932, the gate showed a pointed arch with decorative brick and deep niches on both sides of the passage. In the 1950s, yet another structural weakness led to partial demolition of the top story above the main arch, which reached most of the upper floor of the portal, and after 1953, to a mere curtain appeared above 
its outside façade (Fig. 3). However, some of those modifications, achieved during different periods of those civilisations, have also cemented a more defensive look for the Fortress against any anticipated attack, thus corroborating their tangible impacts within its built context to be inherent in the gate's architectonics.

The location and singularity, which dominate the surroundings, facilitate a smooth slope to the 'Suq' (the traditional market in the lower city) in addition to reflecting a strong impression regarding the site as robustly fortified and impossible to penetrate (Fig. 1). In fact, the progressive and evolving nature of Islamic socio-cultural norms, during periods of Ottoman rule, has contributed to the persistence and authentication of the spatial makeup, and thus the historical record of the gate as a structure of diverse functions (such as courtyard, formal governmental offices, jail, guest spaces, commercial shops, a clinic and horse stables) (HCECR 2008, 2012b; Novacek et al. 2008; Brammah 2009b). Importantly, the accumulated growth of the socio-cultural assets has also materialised within the gate's physical structure, which determined its final form during the Late Ottoman period. The gate's singularity has also contributed to maintaining the social privacy of the site, which in turn assisted in sustaining the strong coherence of the social structure of the settlement; this tradition was subsequently adopted by the Islamic norms during the Late Ottoman period to support the concept of neighbourhood. Religiously, the gate's placement facing the central Mosque of the site, thereby oriented in the same direction of Qiblathe direction of Muslims' Prayer, has granted the site more symbolic-religious value during the Late Ottoman period and beyond (HCECR 2008). In this period, like some of the Middle-East citadels' gates, the gate articulates a panoramic scene of the most important historical periods that record the cultural history of the site, thus attesting to different historical events and cultural values. As a result, it heightens its historical importance and cultural essence, all of which may substantiate its authenticity (HCECR 2008, 2014; Progetti 2012).

The gate's architecture can also acquire its significance through the importance of the site's context since its spatial layout establishes continuity within the context through flexibility and adaptation, which was influenced by diverse civilisations and cultures. However, due to political conflicts within and around the site, delineation of its physical history is vague, and thus, its physical pattern cannot be ascribed to a specific time period within the overall historical chronology of the context. Here, although the gate's historical records are perhaps unable to accentuate a clear physical-historical demarcation during the antiquated time periods of the built context, this cannot simply deprive it from possessing a footprint within the cultural history that the site reflects before the 1730s. The fact that the grand gate was a material witness of the cultural inputs during all of these epochs may robustly entrench its 'authenticity of setting' ultimately, which may enable its perpetuation (HCECR 2012c; Bornberg et al. 2006; SOITM 2013).

\section{A contentious intervention in the gate construction}

As a consequence of the alleged soil breakdown of the Tell, after 1953, which was argued to threaten the foundations of the perimeter wall where the gate stands (Brammah 2009b), the gate experienced a reckless intervention of renovation in the late 1970s, which has enormously altered its architectural structure. The renovation policy declared that the critical structural situation of the gate foundations makes the intervention necessary to salvage the Citadel's overall structural integrity. In fact, built heritage authenticity has usually been driven by different subjective purposes enacted by heritage conservation policies (ICOMOS 1994; Von Droste and Bertilsson 1994; Graham 2002), whereas justifications are often built on retaining heritage physical integrity to resuscitate its cultural significance, which, conversely, often leads to partial loss of this characteristic (Urry 1996; Graham et al. 2000; Dicks 2000). To stop the continuous departure of the site's inhabitants, modern services should have better access to the site (Jasim et al. 2018); therefore, the gate should have its architectural structure substantially renovated. However, the presented solution has resulted in a total substitution of the architectural assets of the original gate, which instead led to jeopardising the historical-cultural significance, thus authenticity of the context (Novacek et al. 2008; UNESCO 2010), which should have been conserved as an outstanding value of the site (Waterton 2005; UNESCO 2010) (Fig. 4).

Although the soil breakdown, including its impacts on the foundations of the site, has been verified by more than one study (Jasim et al. 2018; Jasim et al. 2020), demolition of the original gate in this enigmatic way affirms lack of scientifically-based evidence about the legitimacy of the decision. For example, there were no real on-site investigations, which should presumably recognise some doable priorities, prospects and subsequent solutions, which may sanction the demolition. A series of interviews encompassed 14 professionals among the site's indigenous inhabitants who were inhabiting the site before the evacuation in 2006 and were carefully identified based 

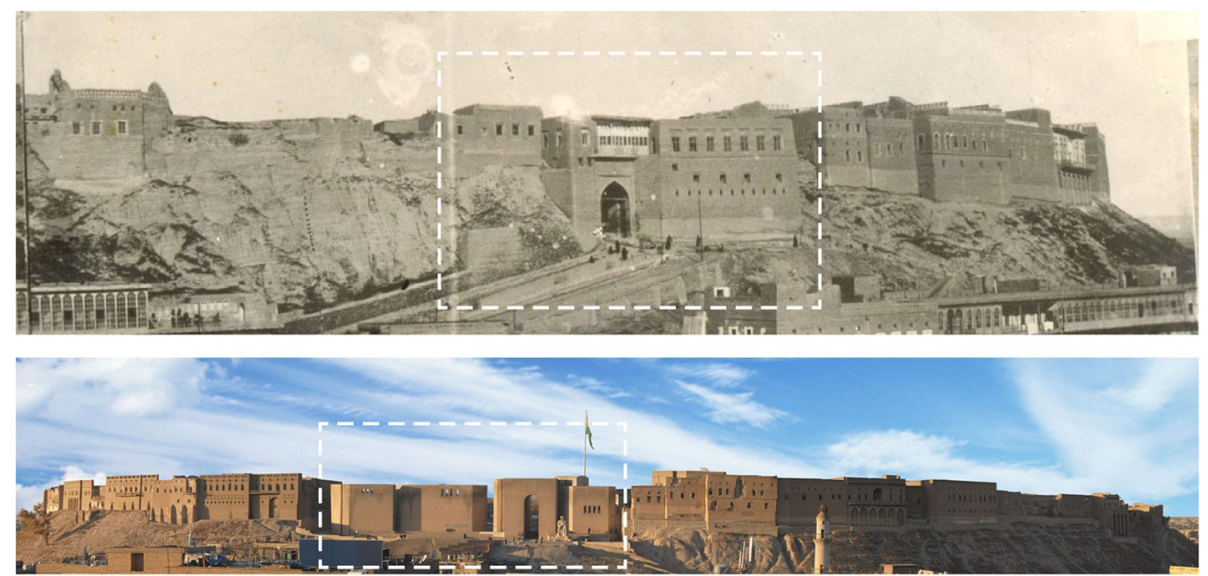

Fig. 4 Above: the original gate of the Citadel after 1930s (Source: HCECR 2012a, 2). Below: the 'BG' of the Citadel after 1970s, displays a new architectural structure as a segmented-abstract linear barrier (Source: site archival data)

on their cultural roots, their cultural experiences and knowledge about the Fortress. In fact, searching for this elite among those inhabitants was a challenge for the study, which may explain why confining the interviews to this number of participants, who ultimately affirmed that the demolition was controversial regarding its novelty and whether it acknowledges the site's historical value in principle. 'All that was done was to remove an old gate and replace it with a new gate', a professional inhabitant said. This process simply 'effaced the cultural values the gate had possessed for a long time, regardless of whether it has truly provided any solution for the site's integrity, and has therefore 'jeopardised the authentic history of its context', said another. Here, most of the interviewees attributed the reason for inaptness of the demolition decision to the fact that it was confined to a 'present plan ... set outside the site ...., while had to be implemented on the Fortress directly'. They related its appalling consequences upon the built context to 'the Iraqi previous regime', contending that 'charging the site with this political implication undoubtedly impacts [its] long history', thus its 'authenticity'. While the reference to the relationship between the demolition and that regime is still vague, as it does not show any concrete evidence whereby this relationship can be substantiated, the political history of the area may detect proof that supports these claims. ${ }^{2}$

In fact, some recent studies have also linked the demolition to some political implications, thus attributing the

\footnotetext{
${ }^{2}$ The contentious genocide of Anfal -which followed the renovation during mid-1980s-, for instance, may certify the regime's destructive policy against the area including its built heritage. Anfal is locally referred to be a consequence of a chemical weapon used against Kurds of Halabja with the blessing of Saddam Hussein during the IraqiIranian war in mid-1980s.
}

deformations of the 1970s within the entire central area of the settlement, to the Saddam Hussein regime. The Brammah \& Huszar Report (Brammah 2009c) provide evidence on the preparations of the master plan of the site's current revitalisation process, which demonstrates that the Citadel's built context confronted a real threat of demolition during the period of the former Iraqi regime. Moreover, the recent HCECR Report (2012a, 2012b, 2012c) for the addition of the Citadel onto the World Heritage List 'WHL' also states that the built context of the site has faced some 'deliberate demolition by the previous regime', which involved its whole central area, including 'the demolition of the gate' (88). Indeed, the loose interventions of that regime on the Babylon heritage site in 1989, which 'resulted in 'the great detriment of the site' and thus [its] temporary exclusion from the WHL', may verify that (Jasim et al. 2018, 87). However, the erroneous top-down policy concerning demolition of the urban context, as part of redevelopment of the sacred area, which surrounds the Shrine of Kadhim in the traditional area of Kadhimiya in Baghdad, can be seen as another example (Jasim et al. 2018). The policy sought to blindly demolish the area even without investigation of its rich historical-cultural assets, changing its urban and architectural characteristics.

Herein, some of the UNESCO Guidelines for the Citadel Revitalisation have perhaps been enacted as openended instructions to offer more flexibility in treating some of its historically controversial structures. For instance, the Guidelines recommend removal of any addition that may distort 'the character' of its urban context, especially if it 'brings about a loss of significance' of its historical value $(2014,125)$. However, it did not suggest how to deal with this addition if it would possibly have been seen as new cultural potential that may enrich the site's history in the long run. Nevertheless, carrying 
out these guidelines literally, the current revitalisation policy sought to remove the BG and reconstruct the old gate instead, as one of 'those buildings' that should be restored 'as quickly as possible' (Brammah 2009b, 36). Accordingly, the decision was made in 2012 to restore the grand gate to its original settings through the new 'PD' (HCECR 2012a), which should have the potential to reinstate 'the spirit of the original use for which the [original gate] was designed', which is regarded as congruous with this condition (UNESCO 2014, 125).

Different criteria have been set to ensure truthful reconstruction, such as using the same deteriorated brick of dilapidated residential units at the site, in addition to manufacturing specific bricks that should reflect the same properties as the ruined bricks of the original gate, such as form, colour, dimensions, texture and material (HCECR 2012c; Brammah 2009a, 2009b). For example, patina (age value-including traces of those warring civilisations, intangibles and bygone cultural ethos) will be re-established based on such an approach of verbatim imitation-based reconstruction, where the value of deep history may also be accurately restored, leading to restoration of the main pointed arch and the two flanking masses of the original gate through the construction of the main part of the $\mathrm{PD}$, which replaced the main central part of the BG. The other two parts of the BG, which are still erect on the site currently, perhaps acknowledge the BG's authority as a material testimony attesting to and documenting a controversial political period within the site's modern history, which may necessitate looking at its inputs regarding the gate's authenticity more critically.

\section{Authenticity and the response to inevitable (politically oriented) heritage changes}

Even though it may be seen as an outcome of the deliberate demolition on the site during the former Iraqi regime, the BG cannot simply be considered a negative political symbol on the site. It manifests historical evidence, which records a specific political-historical period for the site's chronology. Built heritage should also accept some inevitable changes that attest to the significant periods and events experienced by the site (Von Droste and Bertilsson 1994; ICOMOS 1982). As such, the debate about the capacity of the BG to boost Erbil's authenticity may also be shifted from a strict discourse that does not believe in the changes that occur over time to the built heritage into a more flexible dialogue that prioritises such changes, especially if the change might bring new cultural potential to the site. Given the constantly evolving cultural environments of many heritage contexts (Weiler and Gutschow 2017), the interpretation of heritage authenticity should therefore be more progressive and thus should flexibly respond to new themes, traditions and norms these contexts suggest. 'Political chaos' of diverse 'conflicts' and 'issues', for instance, has left noticeable impacts on these contexts to the extent that may combine their new cultural scenarios equally with their tangible assets in any quest towards redefinition of their authenticity (Oyaneder 2019, 187). Such scenarios may constitute a 'wake-up call for leaving aside [...] narratives' that often aim to freeze 'cultural identities' of built heritage to a specific historical period within the chronology of the context thus exposing the context to more realistic propositions (Oyaneder 2019, 190).

Political events have been and still are inevitable in our cultural environments, while their impacts are undeniable and may thus have formed an essential part of our built heritage, causing unprecedented changes regarding its authenticity (ICOMOS 2017). Based on Mitchell $(2008,29)$, authenticity's response to 'the interplay of tangible and intangible values and the dynamic relationship between [heritage] and culture' makes it subject to progression. Authenticity should consequently be seen as an 'evolving' concept within a 'living' heritage context, where its importance cannot be reduced to a specific period nor deny the effects of cruel political events on the context. This makes the concept progressive and developable, constructive and buildable to incorporate new values and thus be self-sustaining over time (Von Droste and Bertilsson 1994), giving legitimacy to the $B G$ as a subsequent inevitable change that is part of such a progressive nature.

Hence, to ensure a lasting protection of the concept, testing the 'authenticity' of the gate should include 'all subsequent...additions' that result from the change, while 'in themselves [should] possess ... values' that can enrich the context both historically and culturally (UNESCO 1977, par. 9; UNESCO 2015, 66). This presupposes that the concept is 'in connection with' any subsequent attributes that the component may add to the site and thus flexibly respond to their impacts (Stovel 2007, 29). Hence, authenticity should be assessed as a composite of values, which together enables a revelation of 'how' the component can advance its progressive nature to become a realistic part of it. However, the concept's overall value should be considered a 'non-renewable' that may have a wider impact on the historical-cultural continuity of the site's context and materials, where criteria such as identity, use and function, and social value and economics should be included (UNESCO 1983; ICOMOS 1996; ICOMOS 2004; Rowny 2004; Stovel 2003, 2004, 4, 2007).

As a recent addition to the Citadel, perhaps the BG corresponds with this discourse, affirming the necessity for investigating this addition, for two reasons. First, the 
discourse suggests a buildable and progressive nature of the concept of authenticity, which may grant the BG more continuity within the Citadel's context. The basis for distinguishing the 'authentic' from the 'inauthentic' of the added component should also entail recognition between what possesses value and what does not. Thus, if the first reason may sustain the BG's existence in the site, the second reason keeps this existence conditional on the level of value that should be demonstrated.

\section{Positioning the BG within this context}

Starting with authenticity as a 'non-renewable' and how the BG supports perpetuation of the original properties of 'context and materials' of the site, and based on the HCECR (2012c), the BG is a 'concrete core [wrapped with modern] brick, featuring a modern abstract monumental style' that entirely contradicts the ancient gate's original materials. The BG's two-dimensional linear structure opposes the context of the original as a compact fabric of traditional spaces (HCECR 2012c, 52). Moreover, 'the abstract approach in its design [as] disconnected sections of wall gives an impression of easy 'permeability' to the Citadel, in contrast to the sense of protection' that the superimposed organic context of the ancient gate granted to the site over three centuries (HCECR 2012c, 52). Therefore, the BG is in contrast to the original gate's properties as 'material and design, handicraft and setting'-identified by the National Park Service (2006) as part of the heritage's nonrenewable authenticity-and thus unable to convey a 'deep spiritual message' sustaining the traditional architecture as 'an inherent part' of the architectural context of the Citadel's outer wall.

However, as a cultural context, the BG is explicitly referred to as part of the 'consequences of political events' on the site by the former Iraqi regime of Saddam Hussein, making it a kind of inevitable change conveying a particular political implication (Brammah 2009a; HCECR 2012c, 69), which may add to the site's cultural context. In this regard, the Declaration of ICOMOS on the Reconstruction of Monuments Destroyed by War ( 1982) states that preservation of any 'inevitable changes' that built heritage may face in the aftermath of any political repercussions is necessary. They are part of the site's cultural story since they have witnessed, and therefore may document, a specific period of its history. Perhaps this, on the one hand, grants the BG the authority to maintain its position as an unavoidable impact on the site that documents this political period, which may act as a 'non-renewable' political-cultural dimension that increases the site's cultural attraction. On the other hand, its removal may deprive the site of one of the most important 'symbols' of its contemporary political history and thus repeat the same mistake of demolishing the ancient gate, thereby creating a new cultural gap in the cultural context of the Citadel.

If the BG's political connotation belongs to the site's recent history and thus may not currently show genuine contribution, it may acquire its value over time to become an integral part of the site's cultural history, and this is the case for many global heritage sites after World War II (Jasim et al. 2018). The war has had a significant impact on them, but this impact has subsequently become a material part of the site, documenting a significant period of history that has been employed as part of the cultural attraction of the heritage. Likewise, the BG may therefore assist in 'creating, recreating and promoting [new] stories and images' about the cultural aspects of the site (Park 2014, 2), which helps to expand the narrative for visitors. Here, Macdonald (2009) affirms that 'heritage can perform [as a] mediator depict [ing] the outcome of particular political [conflict] or even make [it] central' for its visitors (117-118). The context's 'constitutive' nature enables it to continually incorporate any inevitable political event into its evolving cultural makeup, which over time contributes to the cultural values of architectural heritage and thus its authenticity of setting (Collier and Ong 2005, 4).

a) Within this context, the 'Implementation Action Plan' for site revitalisation (2009) endorses any 'changes' that the gate has inevitably undergone as part of its 'authenticity of design' since they document certain cultural impacts. This may dictate delineating 'the concept of authenticity' within a new conceptual frame that recognises the concept as 'neither static nor fixed' but also progressive and buildable (Collier and Ong 2005, 2). Although it may protect the Citadel from superficial additions, authenticity should also be seen for its potential to assimilate new inevitable changes, including their implications, which perhaps keeps the tourist attractions of the site open to progress and thus influential. Evidence for this may come from German built heritage after World War II, which, although the hope was to block the War's deplorable memories, the significant cultural and historical status of some Nazi buildings has strongly dictated their protection and thus their perpetuation within the context (Koshar 1998, 2000). A new reconstruction of the Goethe House, for instance, has strongly been advised to not 'obscure the intimate connection between the heritage of the Goethe's thought and the rise of Nazism' (Koshar 2000, 157). The Goethe House has contributed to its cultural story when it 'helped to create a German tradition of idealism' (Koshar 2000, 157), thus becoming an authentic 
part of the historical urban context of the place. Authenticity's value cannot be dogmatically confined to a particular historical period within the site chronology just because it is age-old locally. Other subsequent periods may also have to be equally emphasised if they have their own cultural inputs within the physical growth of the context. Otherwise, the concept will be no more than a theme nested in past remnants that rejects the cultural progress of the context and thus be reduced to untouchable time-honoured reminiscences. According to Staiff et al. (2013), therefore, decisions on the future of the BG should come through a critical reading of its historical value to determine it as 'authentic' or 'inauthentic' within the Citadel's built heritage. As an authentic value, its political implication may add to the Citadel's cultural attractions that may enrich 'the tourist experience', which can bring more 'international support' for the site's current revitalisation (Macdonald 2009).

Herein, its perpetuation may create global 'historical significance' in the run for the site, since it is part of 'an already completed era of a [political] history that no longer exists in the present' (Rosenfeld 2000, 261). However, the BG architecture should not be 'perceived as an intrusion threatening [architectural] authenticity of the site' (Staiff et al. 2013, 181). To resolve this dualism, its physical structure should respond to the obsolescent architecture of the site and thus demonstrate a kind of 'materials sympathetic' to its antiquated architectural assets (Staiff et al. 2013, 181), whereas contemporaneity of the BG's concrete core confirms the opposite.

b) From the perspective of 'identity' and whether 'the component [boosts] the traditional patterns of use that have characterised the site' (ICOMOS 1996, Parts i-v), the BG's abstract structure (Fig. 1) renounces maintaining the multi-functional role of the ancient gate, which often stood for a unique cultural pattern within the last three centuries of the site (HCECR 2012c). The pattern has granted the gate's structure a perpetual significance, which Stovel (2007) determines as a norm that proves its authenticity, where Von Droste and Bertilsson (1994) consider its functional continuity an essential condition for its perpetuation. Conversely, the BG's architectural pattern detaches its structure from the Citadel's urban context as a unique Islamic pattern, which first lessens its 'authenticity of setting' (Brammah 2009a, 90) as one 'homogeneity [of] architectural typology' (HCECR 2012c, 17). Second, it clashes with the original 'materials and techniques as well as architectural typology and style' of the original gate (HCECR 2012c, 17), which often promoted the architectural identity of the perimeter wall with a clear physical consistency. Hence, it challenges both the 'authenticity of design' and 'authenticity of materials' of the Citadel's built context, exposing its architectural 'identity' to a real weakness (Brammah 2009a, 90).

Although it often reflected a state of singularity, the ancient gate cemented a coinciding spatial relationship with the site's perimeter residential units as a unified synthesis of harmonised architectural elements. However, the gate's carefully tailored location within the typology of the site's main alleyways has also given its functional identity a surplus value when facilitating an easy flow from and to the site (HCECR 2008). This placement grants the ancient gate an authentic form originating from the evolving urban traditions of the Citadel's architecture, which may challenge the BG to possess a similar setting. The site has incorporated different periods of urban norms ingrained by the early, late and post-Ottoman pe$\operatorname{riod}(\mathrm{s})$ (from 1750 to 1960), through which its current urban context settled to attest to its 'authenticity of settings' (Brammah 2009b; HCECR 2012c). However, the BG's intrusive abstractsculpting architecture, according to Novacek et al. (2008), could not respond to these norms when it could not evolve as an integral part of an authentic setting of 'architectural design, structure, materials and details' (HCECR 2012c, 92).

c) As a socio-cultural value (Rowny 2004), the report presented by the HCECR to the ICOMOS indicates that the old gate's pattern is present in the 'memory' of the cultural history of the gate in which the BG's spatial pertinence to the outer wall appears like an 'artificial part' (HCECR 2012c, 113), which seems powerless to maintain this history (ICOMOS 2014). As a result, the report discloses that the BG creates a feeble social affinity with the locals who possess an inherent relationship with the site (HCECR 2012c), making, as per ICOMOS (2008a), this affinity partly subject to what the old gate evokes for them. While a complementary condition is determined for 'social-cultural authenticity', any 'value judgements' assigned by the locals should be taken as a real indicator of the validity of the site's cultural context, thus 'part of [its] traditional continuity' (Ibid, 43). The outcome has yet to lead us to suspect what the BG essentially proposes as a structural solution to protect against possible soil breakdown in the mound (Brammah 2009b).

Finally, from the perspective of responding to the Citadel context as a 'composite' of authentic assets 
(Stovel 2007), the BG weakens its structure to conform to the cultural periods of the site, and thus 'the cultural contexts to which [it] belongs' (ICOMOS 1994, Article 11). The site comprises different cultural layers that started in the NeoAssyrian era until after the 'post-Ottoman period' (Brammah 2009a; HCECR 2012c, 42). The site's current predominant post-Ottoman Islamic architectural pattern involves many architectural and cultural relics beneath, mainly showing traditional functions of 'early [and] Late Ottoman periods' (HCECR 2012c, 42). They stretch back to embrace the cultural and architectural remnants of the previous civilisations to the Neo-Assyrian era that truly reduces the ability of the BG's brief duration and abstract structure to comply with such historicalcultural relics.

\section{Discussion}

Indeed, the BG fails to match the Citadel's authenticity of setting, design and material. However, there is an imperative matter that perhaps should be debated here. Although place-based synchronic reading of authenticity is important, in the issue of the BG, it might be equally important to shift the debate towards time-based diachronic reading of the concept. Political implications, as aftermaths of some incessant conflicts, have become an integral part of the physical entity, thus cultural strata, of many built heritage sites, which left irreversible impacts on their authenticity that may impose a constant re-substantiation of the concept. In this regard, a probe of the BG's cultural impacts on the site's authenticity should consider not only the place where it rests but also the time that it represents (Nezhad et al. 2015) and thus should comply with the notion of 'progressive authenticity' (Von Droste and Bertilsson 1994). Although some add-ons to some heritage sites were initially perceived as devastating political interventions, over time, they started to demonstrate a new cultural status as part of their cultural history. For instance, Nuremberg Nazi's heritage was first claimed to be forbidden from any attempt at conservation due to the concern that 'restoring Nazi buildings might give them power' to entice the audience into 'sympathy with the Nazi project' (Macdonald 2009, 131). However, its inclusion in conservation plans has subsequently been sanctioned based on the fact that 'Nuremberg and its citizens should publicly acknowledge their ... heritage' as a 'historical generator' to be 'reminding for the sake of the future', 'warning' of 'terror' first, and simultaneously 'guarding' as 'the beginning of Human Rights' (Macdonald 2009, 128/130). This may enable the perpetuation of the Nazi heritage as material evidence of a crucial period within the political history of the place, while it 'does not necessarily lessen the crimes committed by the Nazi' (Macdonald 2009, 129). Conversely, it can stand as a witness of that by adding a new cultural layer to the cultural relics of Nuremberg's built context, thus boosting its authenticity of setting, while opening the site towards more tourism potential. 'Mediatory effects of materiality' of the Nazi heritage can cement the context with more cultural attractions based on their 'connotations as constitutive parts' of the contentious course of political events during Nazism (Macdonald 2009, 131).

Accordingly, regardless of their initial outcomes, such political implications are possibly able to demonstrate some cultural potential and can subsequently be considered cultural merits for the context, and this perhaps is the case for the BG. The scrutiny of authenticity discourse regarding the BG should therefore depart from the 'narrow restriction to the purely material side' of the component, thus its 'age value', but rather incorporate the discourse in a 'transcultural status' instead (Weiler and Gutschow 2017, 2-4). Authenticity should not always be completely concerned with what is 'original', as an attribute inherent in the past. The concept cannot totally be ascribed to the historical value of those dilapidated physical parts just because they are 'original' (ICOMOS 1965, Article 9), although their physical integrity evidence periods within the historical chronology of the site (Denslagen 1994, 2009). The old tradition claiming that 'the interest attached to the new will owe itself...to the authenticity of the old [parts]' might need to be revisited in such cases (Marshall 1923, 9-10). Recently, authenticity has also started to be venerated through traces of successive cultures blended in the built context, whereby the concept has been accorded diverse floating social, political and other cultural 'meanings', while these meanings also shift their grounds over time (Weiler and Gutschow 2017, xviii). In this regard, the ICOMOS Declaration on Monuments Destroyed by War (ICOMOS 1982), compatible with the Nara Document (1994), rejects judging authenticity 'within fixed criteria' (3), since this may curb the mediatory effects of these meanings, which may add to the site's authenticity later (Macdonald 2009). This should permit the concept to be furthered with any new cultural inputs resulting from outcomes of these effects, for which Von Droste and Bertilsson (1994) suggest approaching authenticity progressively, which affords more justification for the BG's continuation on the site. Erbil Citadel's built heritage brings diverse temporal orders together with different mediatory effects; thus, its authenticity should truthfully embody connotations of these effects, including those that emerged as part of contentious political implications which the BG seems part of, since this may enrich the site's historical-cultural inputs. 
Hence, authenticity persists as a 'relative concept' rather than being 'an absolute qualifier', which often imposes its presence based on some 'particular attributes' acquired over time within the site's life span, while their contribution to the concept may emerge successively as latent 'recognised values' (Stovel 2003, annex 4). In addition to its original values, this makes authenticity relatively 'rooted' in these newly recognised values; therefore, their acknowledgement is requisite basis' for its assessment (ICOMOS 1994, 9). Thus, if the BG's structure was added during a controversial period of the site's history, this should consequently be re-considered in the assessment of Erbil's authenticity, whereas the 'original intentions' of its cultural-political story should be retained more flexibly (Von Droste and Bertilsson 1994, 3). Rebuilding the PD replica on the residue of the $\mathrm{BG}$, conversely, may challenge the authenticity of the former, 'as removing the physical remains of certain eras', which perpetuate a particular political-historical record, 'generates controversy for not respecting historical authenticity' of such a record (Su et al. 2020). Removal of the BG otherwise would be the equivalent of a repression of the context's political past, which could serve as a vital tourist venue that informs about this past. Perpetuation of the BG, as a political monument at the site, instead may help-as Nazi heritage does - to recognise it as a kind of 'warning heritage', which reminds us of the past.

However, the BG cannot present a real 'creative engagement with how to make relevant the [old gate] in the present' while maintaining its authentic features (Alivizatou 2012, 139). It thus cannot corroborate inherent sitebased historical values, which debilitates its structure to substantiate 'historical-evidential authentication' (Jokilehto 2007), thus enervating its identity (Nezhad et al. 2015). However, this 'authentication' also accepts any meaningful impact that embodies the time of the change, which may prioritise the BG's political denotations since this may add to the site's modern history. Accordingly, it can be argued that although the mechanism whereby it has been added to the site breaks 'the stable dimension of authenticity', being part of inevitable political aftermaths still proves a cultural identity for the BG that evolves as 'part of ... dynamic authentication' of the settlement (Nezhad et al. 2015 , 102). From a touristic perspective, perpetuation of the BG through the very controversial global political reputation of Saddam Hussein can nourish Erbil's built context with new tourist cultural-political potential. In addition to local visits, this may promote global visits, particularly those who are curious about knowing the tangible impact of such political figures on global heritage. Full removal of the BG may otherwise reduce foreigners' desire to visit, thus losing financial support, while heritage tourism 'is a money or currency question' ultimately (Wachter 1999, 325).
Evidence for this comes from the restoration of some Nazi historic buildings in Nuremberg city, which became 'territorialized [and] not only as part of a heritage assemblage, with its capacities to ensure durability and confer worth but also as part of the assemblage of Nuremberg and its citizens' (Wachter 1999, 325). Based on Wang and Bramwell (2012), this places 'political economy' as one of the substantial aspects in planning for 'heritage protection and tourism development' (988). As such, the appropriate approach of conservation might entail tackling the issue of the BG as a kind of heritage-based political economy, which therefore should emphasise it as a reconstructed traditional-style culture. This can also increase visitors' verbal support for such a transformative heritage, being a local tourism-related commodification (Wang and Bramwell 2012; Su et al. 2020). Indeed, the clash between the context's historical value and such political conflicts, if wisely used, may materially contribute to the transformative procedure of heritage-based tourist destinations of the site. Traditional-style culture simply implies that some politicalcultural scenarios can be deliberately maintained to serve more tourist-economic needs related to the site ( $\mathrm{Su}$ et al. 2020, 1). Thus, the BG's authenticity may come from its ability 'to express cultural significance through its...intangible values' embedded in the site as part of inevitable political implications that, first promote the current tourist destinations of Erbil, and then engrave a new cultural layer to its contemporary history (ICOMOS 2017, 11).

\section{Conclusion}

Authenticity is evident that is not engraved in stone. Authenticity is a value that responds to existential events in which built heritage reminiscences are perpetuated. This makes heritage authenticity's definition inherent in its fabric; thus, its persistence is subject to continuous cultural accumulations owing to the disparity of the site's cultural contexts. When built heritage contexts witness some inevitable interventions, the authenticity concept should not be vulgarly employed as a 'mantra' to disguise any political inputs that may result from such interventions, cementing otherwise its 'meaninglessness'. The concept's cultural dimension is malleable, constantly producing processual configurations contingent on the actual rehearsal of sitespecific practices and its transcultural properties, which these interventions are usually part of. Hence, political intervention-based material encroachments on heritage should be carefully touched and only to avert 'further decay', yet truthfully conserved to 'authenticate memory' of the site's cultural history.

In this regard, the existence of some dilapidated heritage components associated with some contentious political repercussions should be preserved in their ruined state as a memorial witness of a particular political period of the context's history. Their perpetuation on 
the site is a genuine physical documentation of such repercussions within its cultural context. Otherwise, restoring some bygone physical residues at the expense of such repercussions may 'destroy the veracity' of the context, since their physical-cultural aftermaths have become an integral part of the context. Reinstatement of the original gate, in return, may require adequate physical evidence of that gate, which should be on the site, to be a true restoration rather than a pure reinvention the PD produces. New reconstruction material cannot ensure outright representation of authenticity by itself but perhaps the inherent cultural value in the permanence of the physical component. Built heritage authenticity is more valuable to be redefined through pseudo reconstruction, a matter that mostly results from marginalising the time dimension's potential of immaterial merits of heritage cultural inputs in enhancing the concept. Thus, the trend to reinstate what was lost of the context is perhaps no more than being a state of nostalgia, which can therefore be labelled an "inventive mimesis" towards truthful reinstatement of the gate's authenticity. Although it has fruitful outcomes within certain conservation policies, the contribution the PD's mimesis produces for the gate's authenticity seems controversial. Its restoration principles apparently do not genuinely submit to clear conservation rules, which may require more investigation in this regard, which this paper recommends as a future study.

According to its interrelated assets, authenticity should not be assessed 'as if it were an absolute concept'. As part of its progressive nature, authenticity should instead be approached as a meaningful existential issue of a 'transcendental value', where its cultural dimensions cannot be grasped directly from the outside form without distilling its essence to reveal what is implicit. As such, the BG entails truthful consideration of its incorporation as a realistic part of the Citadel context's cultural accretion. Although built heritage has the right to emerge from conservation processes in 'dignity', this does not mean freezing its physical context 'as it is found'. Built heritage should respond to its cultural strata and thus should acknowledge any new inevitable component resulting from any cultural repercussions that the context has controversially experienced. The BG documents a certain political period, which cannot simply be negated or even considered as a banal history; thus, its total demolition may efface a true period from the site's cultural history. The remaining current material settings of the BG should thereby be preserved as part of the site's spatio-temporal continuity, as its inevitable cultural input adds to the site's cultural layers, augmenting its long-term authenticity.

Acknowledgements

Not applicable.
Authors' contributions

Mohammed Awadh proposed the idea, conceived of the study, structured the argument, conducted the field work and data collection, drafted the article and completed the writing. While both of Laura Hanks and Katharina Borsi have elaborated the study design and deepened its scientific value. The three authors read and approved the final manuscript.

Funding

Not applicable.

Availability of data and materials

Not applicable.

\section{Declarations}

\section{Competing interests}

The author declare that they have no competing interests.

\section{Author details}

'Department of Architectural Engineering, Koya University, University Park, Danielle Mitterrand Boulevard, Koya, Kurdistan Region KOY45, Iraq. ${ }^{2}$ Department of Architecture and Built Environment, University of Nottingham, Room B35, Lenton Firs, University Park, Nottingham NG7 2RD, UK.

Received: 19 November 2019 Accepted: 24 May 2021

Published online: 05 July 2021

\section{References}

Alivizatou, Marilena. 2012. Debating heritage authenticity: Kastom and Development at the Vantuana Cultural Centre. International Journal of Heritage Studies 18 (2): 124-143. https://doi.org/10.1080/13527258.2011. 602981.

Beijing Document on the Conservation and Restoration of Historic Buildings in East Asia. Adopted by the International Symposium on the Concepts and Practices of Conservation and Restoration of Historic Buildings in East Asia, Beijing 24 to 28 May 2007.

Bornberg, R., M.A. Tayfor, and M. Jaimes. 2006. Traditional versus a Global, International style: Arbil, Iraq Institute for Comparative Research in Architecture.

Brammah, M. 2009a. Revitalisation of Erbil Citadel-Iraq-phase I, Final Report: Summary of Activities and Outputs of the Project. Brammah Huszar \& Associates.

Brammah, M. 2009b. Revitalisation of Erbil Citadel -Iraq-, Phase I, Final Report: Implementation Action Plan. Brammah Huszar \& Associates.

Brammah, M. 2009c. Conservation Master Plan Exhibition, a presentation from 9 pages delivered by Michael Brammah on "A Vision for the Future of the Citadel" in the UNESCO/HCECR Workshop: The Future of Erbil Citadel: Towards a World Heritage Nomination.

Collier, Stephen J., and Aihwa Ong. 2005. Global Assemblages, Anthropological Problems. In Global Assemblages: Technology, Politics, and Ethics as Anthropological Problems, edited by Aihwa Ong and Stephen Collier, 3-21. Oxford: Blackwell.

Conran, Mary. 2006. Commentary: Beyond authenticity: exploring intimacy in the touristic encounter in Thailand. Tourism Geographies 8 (3): 274-285. https:// doi.org/10.1080/14616680600765230.

Denslagen, Wim. 1994. Architectural restoration in Western Europe: controversy and continuity. Amsterdam: Architectura \& Natura Press.

Denslagen, Wim. 2009. Romantic modernism. In Nostalgia in the world of conservation, translated by Donald Gardner. Amsterdam: Amsterdam University Press.

Dicks, Bella. 2000. Heritage, Place and Community. Cardiff: University of Wales Press.

Golomb, Jacob. 1995. In search of authenticity: existentialism from Kierkegaard to Camus. London: Routledge.

Graham, Brian. 2002. "Heritage as Knowledge: Capital or Culture?" Urban Studies 39 (5-6): 1003-1017.

Graham, Brian, Greg Ashworth, and John Tunbridge. 2000. A geography of heritage: power, culture and economy. London: Arnold Publishers.

Gutschow, N. 2010. Towards a transcultural discourse in donservation and restoration: review and outlook. In Conservation and preservation. Interactions 
between theory and practice. In memoriam Alois Riegl (1858-1905), edited by Michael S. Falser and Michael Lipp and Andrzej Tomaszewski, 11-17. Firenze: Editioni Polistampa.

Han, Byung-Chul. 2011. Shanzai-Dekonstruktion auf Chinesisch. Berlin: Merve Verlag.

HCECR. 2008. www.erbilcitadel.org [online]. Erbil: HCECR Available: http://www. erbilcitadel.org/index.php.

HCECR. 2012a. Erbil Citadel: reinstatement of the grand gate.

HCECR. 2012b. Highlights of ErbilCitadel: history and architecture: visitor guide.

HCECR. 2012c. Nomination of Erbil Citadel (Kurdistand Region, Iraq) for Inscription on the UNESCO World Heritage List; Vol. I.

HCECR. 2014. Governorate guide book final text with photos.

ICOMOS. 1965. "International Charter for the Conservation and Restoration of Monuments and Sites (The Venice Charter)." Approved by the Second International Congress of Architects and Technicians of Historic Monuments in Venice from 25 to 31 May 1964, adopted by ICOMOS in 1965.

ICOMOS. 1982. Declaration of Dresden on the "Reconstruction of Monuments Destroyed by War" (1982).

ICOMOS. 1994. The Nara charter on authenticity 1994

ICOMOS. 1996. The declaration of San Antonio 1996.

ICOMOS. 2004. Principles for the conservation of heritage sites in China. The Getty Conservation Institute.

ICOMOS. 2008a. The world heritage list: What is OUV? Defining the outstanding universal value of cultural world heritage properties. An ICOMOS Study Compiled by Jukka Jokilehto, W. C. F. C. C., Michel Parent and Michael Petzet. Berlin.

ICOMOS. 2008b. Québec Declaration on the Preservation of the Spirit of Place. Adopted at Québec, Canada, 4 October 2008.

ICOMOS. 2014. Evaluations of nominations of cultural and mixed properties: ICOMOS report for the world heritage committee 38th ordinary session, Doha, June 2014.

ICOMOS, 2017. Approaches to the conservation of twentieth--century cultural heritage Madrid-New Delhi Document 2017

Jasim, Mohammed A., Laura Hanks, and Katharina Borsi. 2017. Do really the audience's views efficiently boost built heritage conservation policies? Athens Journal of Tourism 4 (4): 283-306.

Jasim, Mohammed A., Laura Hanks, and Katharina Borsi. 2018. Repercussions of singularity of site authorities in making heritage conservation decisions: evidence from Iraq. Built Heritage 2 (1): 77-91.

Jasim, Mohammed A., Laura Hanks, and Katharina Borsi. 2020. When marginalising the role of local participation in heritage conservation policies: evidence from Erbil Citadel. Athens Journal of Tourism 7 (1): 17-40.

Jokilehto, Jukka. 2007. International charters on urban conservation: some thoughts on the principles expressed in current international doctrine. City \& Time 3 (3): 2.

Koshar, Rudy. 2000. From Monuments to Traces: Artifacts of German Memory, 1870-1990. Berkeley: University of California Press.

Little, Barbara, and Paul Shackel. 2014. Archaeology, heritage, and civic engagement: working toward the public good. New York: Routledge.

Lowenthal, David. 1998. Authenticity? The Dogma of Self-delusion. In The heritage crusade and the spoil of history, 184-192. Cambridge: Camridge University Press

Lowenthal, David, and Simon Jenkins. 2011. Prizing the past for the present and the future. British Academy Review 18: 34-40.

Macdonald, Sharon. 2009. Reassembling Nuremberg, reassembling heritage. Journal of Cultural Economy 2 (1-2): 117-134. https://doi.org/10.1080/175303 50903064121

Marshall, John. 1923. Conservation manual. A handbook for the use of archaeological officers and others entrusted with the care of ancient monuments. Calcutta: Superintendent Government Printing, India

Mitchell, Nora. 2008. Considering the authenticity of cultural landscape. APT Bulletin 39 (2/3): 25-31.

National Park Service. 2006. Application for inclusion of a property in the U. S. World heritage tentative list.

Nezhad, Somayeh Fadaei, Parastoo Eshrati, and Dorna Eshrati. 2015. A definition of authenticity concept in conservation of cultural landscapes. International Journal of Architecture Research 9 (1): 93-107.

Novacek, Karel, Tomáš Chabr, David Filipský, Libor Janíček, Karel Pavelka, Petr Šída, Martin Trefný, and Pavel Vařeka. 2008. Research of the Arbil Citadel, Iraqi Kurdistan, first season. Pamatky Archeologicke 99: 259-302.
Oyaneder Rodríguez, Adrián. 2019. Book review a future in ruins: UNESCO, World heritage, and the dream of peace by Lynn Meskell. Archaeological Review from Cambridge 34 (1): 187-190.

Park, Hyung Yu. 2014. Heritage tourism. Abingdon: Routledge.

Poria, Yaniv, Arie Reichel, and Avital Biran. 2006. Heritage site management: motivations and expectations. Annals of Tourism Research 33 (1): 162-178.

Progetti, A. R. S. 2012. A.R.S. Progetti's Protection: working for the public administration in Iraqi Kurdistan. ARS Progetti S. P. A.

Rosenfeld, Gavriel D. 2000. Munich and memory. Architecture, monuments, and the legacy of the third Reich. Berkeley: University of California Press. https://doi. org/10.1525/9780520923027.

Rowny, Barry. 2004. Charters and the ethics of conservation: a cross-cultural perspective. PhD diss., University of Adelaide.

SOITM 2013. Erbil city. Iraqi Turkmen Human Rights Research Foundation.

Staiff, Russell, Robyn Bushell, and Steve Watson. 2013. Heritage and tourism: place, encounter, engagement. Abingdon: Routledge.https://doi.org/10.4324/97802 03074619.

Stovel, Herb. 2003. From commentaries included in annex 4, The operational guidelines for the implementation of the world heitage convetion, UNESCO WH Centre, version prepared by the Advisory Bodies. 2003.

Stovel, Herb. 2004. Authenticity in conservation decision-making: the world heritage perspective. Journal of Research in Architecture and Planning Conservation and Cultural Heritage 3 (3): 4.

Stovel, Herb. 2007. Effective use of authenticity and integrity as world heritage qualifying conditions. City \& Time 2 (3): 21-36.

Stovel, Herb. 2008. Origins and influence of the Nara document on authenticity. APT Bulletin 39 (2/3): 9-17.

Stubbs, John. 2009. Time honored: a global view of architectural conservation. New Jersey: John Wiley \& Sons Inc.

Su, Xiaoyan, Gary Gordon Sigley, and Changqing Song. 2020. "Relational Authenticity and Reconstructed Heritage Space: A Balance of Heritage Preservation, Tourism, and Urban Renewal in Luoyang Silk Road Dingding Gate." Sustainability 12 (14). https://doi.org/10.3390/su12145830.

UNESCO. 1977. Operational guidelines for the implementation of the world heritage convention.

UNESCO. 1983. Convention concerning the protection of the world cultural and natural heritage: world heritage committee seventh ordinary session; Florence (Italy), 5-9 December 1983.

UNESCO. 2005. Operational guidelines for the implementation of the world heritage convention. Paris, 2 February 2005.

UNESCO. 2010. World heritage tentative lists: Erbil Citadel. https://whc.unesco. org/en/list/1437/

UNESCO. 2014. Erbil Citadel conservation guidelines and manual for implementation, prepared by Ms. Patrizia Barucco and Ms. Lorenza Nicosia.

UNESCO. 2015, Revisiting Kathmandu: safeguarding living urban heritage, International Symposium Kathmandu valley

Urry, John. 1996. How societies remember the past in theorizing museums. London: Routledge.

Von Droste, Bernd, and Ulf Bertilsson. 1994. Authenticity and World Heritage. In Nara Conference on authenticity: Proceedings, edited by Knut Einar Larsen. Paris: World Heritage Centre.

Wachter, C. 1999. Kultur in Nurnberg 1945-1950. Kulturpolitik, kulturelles Leben und Bild der Stadtzwischen dem Ende der NS-Diktatur und der Prosperitat der funfziger Jahre, Stadtarchiv Nurnberg, Nuremberg.

Wang, Yi, and Bill Bramwell. 2012. Heritage protection and tourism development priorities in Hangzhou, China: a political economy and governance perspective. Tourism Management 33 (4): 988-998. https://doi.org/10.1016/j. tourman.2011.10.010

Waterton, Emma. 2005. Whose sense of place? Reconciling archaeological perspectives with community values: cultural landscapes in England. International Journal of Heritage Studies 11 (4): 309-325.

Weiler, Katharina, and Niels Gutschow. 2017. Authenticity in architectural heritage conservation: discourses, opinions, experiences in Europe, South and East Asia. Springer. https://doi.org/10.1007/978-3-319-30523-3.

Wright, G. R. H. 2001. Restoration of Hindu temples in South India and its conceptual background. In East and West, edited by Beniamino Melasecchi and Elisabetta Valento. Vol. 51, Nos. 1-2 (June), 179-184.

\section{Publisher's Note}

Springer Nature remains neutral with regard to jurisdictional claims in published maps and institutional affiliations. 